\title{
LOW-CYCLE FATIGUE OF COLD-DRAWN TYPE 304 AUSTENITIC STAINLESS STEEL IN ANNEALING CONDITIONS
}

\author{
Ambar Pambudi, MoHammad Badaruddin*, \\ SUGIYANTO \\ Study Program of Magister in Mechanical Engineering, Post-graduate Program, Universitas \\ Lampung, Bandar Lampung 35145, Indonesia \\ *Corresponding author: mbruddin@eng.unila.ac.id \\ (Received: 26 January 2022; Accepted: 27 February 2022; Published on-line: 01 July 2022)
}

\begin{abstract}
Type 304 austenitic stainless steel, or better known as SS304, generally has alloying elements: C $<0.1 \%$, Cr $18-20 \%$, Fe $66-74 \%$, Mn $<2 \%$, Ni $8-10.5 \%$, P $<0.045 \%$, $\mathrm{Si}<1 \%$, and $\mathrm{S}<0.030 \%$. In general, this material has good ductility, high tensile strength, and excellent corrosion resistance. In application, type SS304 will be subjected to repeated loading, and eventually, the material will undergo plastic deformation, which leads to structural failure in a short life. The failure of SS304 is generally due to the inability of the material to repeat loading, which results in large amounts of plastic deformation so that the SS304 will experience fatigue and then fracture. Based on the description above, this study aims to evaluate the LCF properties of 304 CDS stainless steel with annealing heat treatment. The parameter used was the strain amplitude $0.003-0.013 \mathrm{~mm} / \mathrm{mm}$. The results of this study revealed that the highest fatigue life in the LCF test was experienced by steel with heat treatment at an amplitude of $0.003 \mathrm{~mm} / \mathrm{mm}$ with 48367 cycles. In contrast, at the amplitude condition of $0.013 \mathrm{~mm} / \mathrm{mm}$, the fatigue life of the steel decreased drastically with the resulting plastic strain being larger, namely $0.0094 \mathrm{~mm} / \mathrm{mm}$ and elastic strain of $0.0035 \mathrm{~mm} / \mathrm{mm}$, with an average modulus of elasticity of $194 \mathrm{GPa}$. Annealing treatment conditions experienced decreased mechanical strength but tended to be ductile. Using Basquin-Coffin-Manson Equation, empirical equations to predict LCF of 304 stainless steels can be determined.
\end{abstract}

KEYWORDS: Steel, SS304, low cycle fatigue, annealed.

\section{INTRODUCTION}

Type 304 austenitic stainless steel, or better known as SS304, generally has alloying elements: C <0.1\%, Cr $18-20 \%$, Fe $66-74 \%$, Mn $<2 \%$, Ni $8-10.5 \%$, P <0.045\%, Si <1\%, and $\mathrm{S}<0.030 \%$. In general, this material has good ductility, high tensile strength, and excellent corrosion resistance. One of its uses is fossil fuels, cooling coils, pressure vessels, valves, textile equipment, nuclear vessels, feedwater tubing, evaporators, and piping systems for highpressure gases [1].

The properties and capabilities of 304 austenitic stainless are widely used in all field sectors with several conditions that must be met to be perfectly applied following the application [2], as in the application of heat treatment to materials to improve the mechanical properties of a material. The cold tensile manufacturing process or cold drawing will increase mechanical properties in the form of increased ductility. Cold drawing has been developed commercially on 304 stainless steels in cylinders, pipes, or high-pressure vessels. 
In application, type 304 stainless steel will be subjected to repeated loading, and eventually, the material will undergo plastic deformation, which leads to structural failure in a short life. The failure of 304 stainless steel is generally due to the inability of the material to repeat loading, which results in large amounts of plastic deformation so that the 304 stainless steel will experience fatigue and then fracture [3].

Fatigue is a material failure that occurs in the structure due to dynamic loads that tend to rise and fall. The dynamic load occurs under yield strength for a long time and, of course, repeatedly. Fatigue in the plastic state below $10^{4}$ cycles is called low cycle fatigue. Meanwhile, fatigue in elastic conditions between $10^{4}$ and $10^{7}$ cycles is known as high cycle fatigue.

In this case, the plastic deformation resulting from cold drawing in the 304 stainless steel material will significantly affect its fatigue behavior. The low-cycle fatigue properties and parameters of materials can be a major consideration in the design of structural members, where the predicted structure is still within safe limits despite experiencing large plastic deformation [4].

Moreover, mechanical properties of materials, such as modulus of elasticity, yield strength, maximum tensile strength, elongation, and cross-sectional area reduction, are the most basic parameters in the design of components and structural elements. Material structures that operate under dynamic or fluctuating load conditions tend to experience a decrease in performance over time the components operate. The decrease or degradation of the strength of the material due to load fluctuations is known as fatigue, which seriously affects the material's behavior on the structural member during working conditions [5]. Therefore, the structural design must consider the fatigue strength of the material to prevent unexpected structural failure due to fatigue.

A study [6] examined cold drawn type 316 stainless steel, tested for low cycle fatigue. The softening cycle occurred at strain amplitudes of $0.31 \%$ and $0.35 \%$. Cold-drawn type 316 stainless steel provided higher fatigue life with strains below $80 \%$. In addition, the interaction between dislocation and twinning was observed during the cycle; it resulted in uniform deformation and delayed crack initiation in 316 austenitic stainless steel. Also, a previous study [7,8] was carried out on 304 stainless steel, which had been annealed. After being annealed, the fatigue life of 304 stainless steel increased by $6.95 \%$. The increase in fatigue life of the material was seen when the material was annealed.

Type 304 austenitic stainless steel has relatively high mechanical strength, large ductility, and good corrosion resistance. Material components often experience shutdown and starting conditions during application due to the maintenance process. In addition, the geographical conditions where earthquakes frequently occur greatly affect the material's properties, which causes the material to undergo plastic deformation, as is often the case in Indonesia. Some of these factors must be taken seriously in designing engineering components, which involve the structural performance of materials undergoing plastic deformation. For this reason, the evaluation of fatigue performance and fatigue life becomes an essential content in a safe design against fatigue failure to be carried out.

However, technical components, such as pipes made of type 304 stainless steel through cold drawing, have not been widely conducted or even carried out by several overseas researchers. The cold-tensile manufacturing process developed on structural components of high-alloy low carbon steel (304 austenitic stainless steel), generally improves mechanical strength performance with good material ductility $[9,10]$. 
The objective of this paper is Low-Cycle Fatigue of Cold Drawn Type 304 Austenitic Stainless Steel with Annealing Treatment. Microstructural analysis and observation of the fracture cross-section of the sample would be carried out after the material was tested under low cycle fatigue conditions to explain the fatigue failure mechanism during the test

\section{RESEARCH METHODS}

Cold-drawn type 304 stainless steel had a shaft or cylinder shape of $15 \mathrm{~mm}$ in diameter and $220 \mathrm{~mm}$ in length. Tensile test specimens were prepared according to ASTM E8 standards, while low cycle fatigue test specimens were prepared following ASTM E606 standards.

Tensile test specimens were shaped according to ASTM E8 standards (Figure 1). Meanwhile, the dimensions and sizes of the low-cycle fatigue test specimens were made under the ASTM E606-92 standard (Figure 2). Tensile test results were plotted in the form of a stressstrain curve. The stress-strain hysteresis curve at half-cycle of fracture life $(0.5 \mathrm{Nf})$ was also plotted. Low cycle fatigue analysis was then performed based on the plastic strain and elastic strain data using the Coffin - Manson - Basquin approach to determine the low cycle fatigue parameters of type 304 stainless steel.

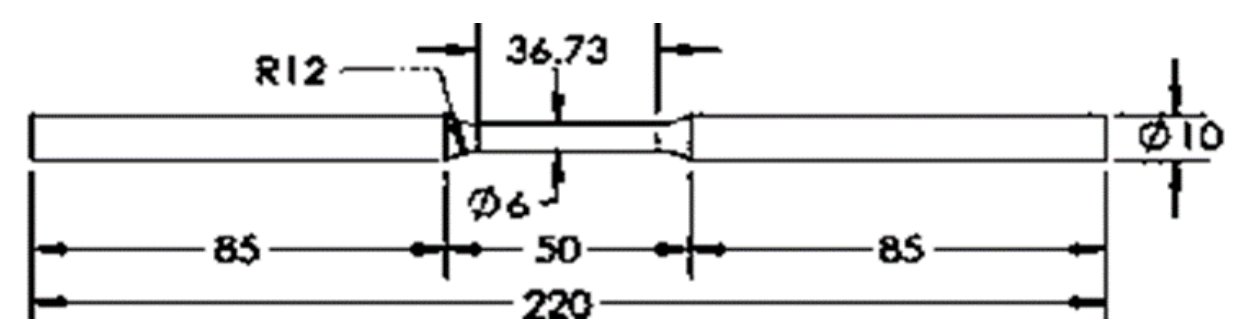

Fig. 1. Tensile test specimen shape and size [11]

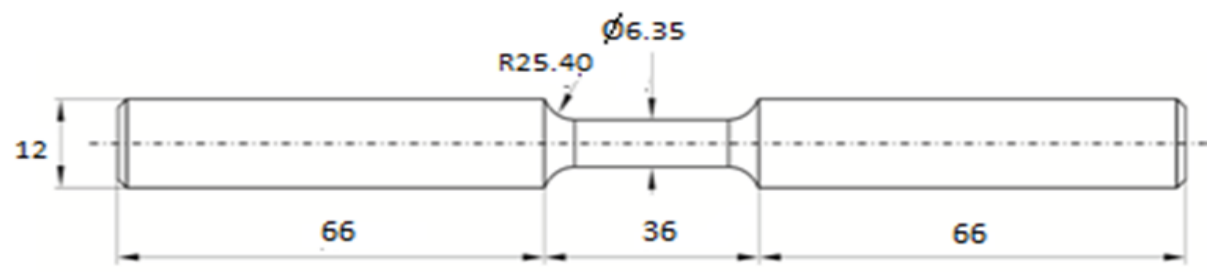

Fig. 2. Low-cycle fatigue test specimen's shape and size [12]

\section{RESULTS AND DISCUSSION}

\subsection{Analysis of Mechanical Properties of Type 304 Stainless Steel}

The following is the tensile test result data in the stress vs. strain curve (Fig. 3.). Based on Table 1, the average static tensile test results of 304 stainless steel obtained different values. The result of cold drawing treatment on 304 stainless steel could increase the plastic area, which can be seen in the increased plastic energy value $(\mathrm{kJ})$ in the annealed specimens. It could improve the low cycle fatigue properties of the steel because the steel underwent a wider plastic deformation during the low cycle fatigue test process. The effect of the annealing treatment, namely the mechanical properties of 304 stainless steel, increased, which can be seen based on the increase in the yield stress and ultimate tensile stress values. The yield stress and ultimate tensile stress values increased significantly in the annealed specimen compared to the untreated 
specimen. Meanwhile, yield and ultimate stress did not significantly differ between the annealed specimens with different holding times.

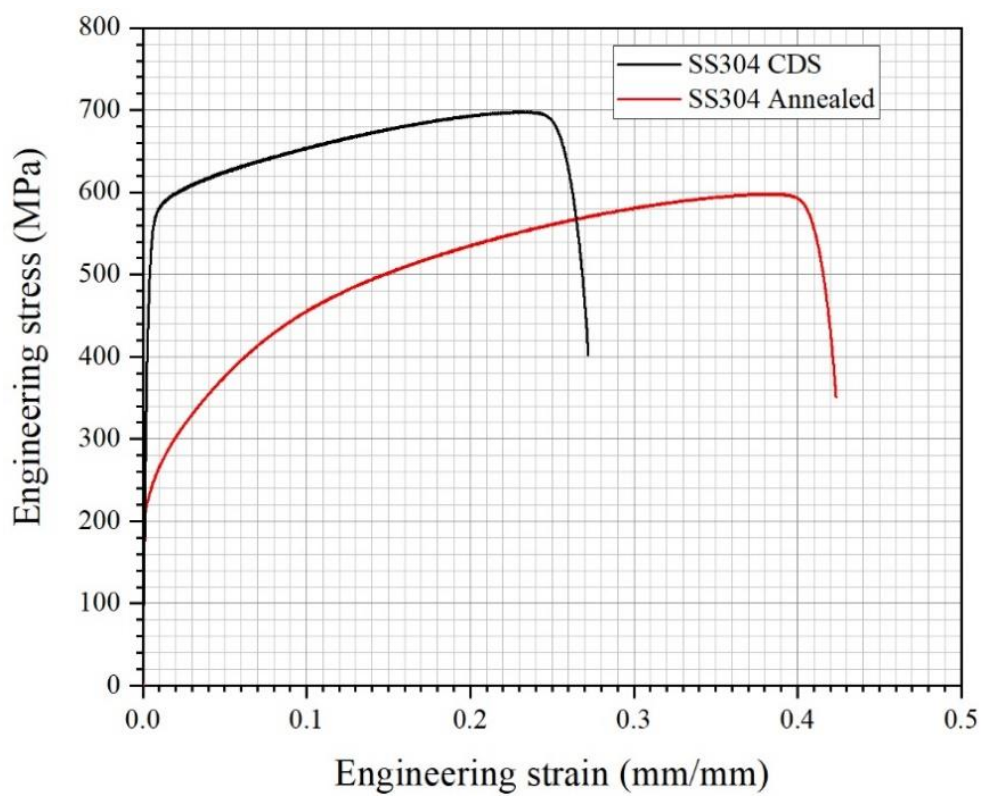

Fig. 3. The curve of stress vs. strain in type 304 stainless steel with annealing treatment

The yield stress and young modulus values for the low cycle fatigue test parameters were taken from the tensile test results of specimens with annealing treatment. The annealed specimen (SS304 Annealed) produced a yield stress value of $220.545 \mathrm{MPa}$ and ultimate tensile stress of $594.87 \mathrm{MPa}$. In addition, the value of the young modulus of type 304 stainless steel, which can be determined using the least-squares method with a linear range of curves vs. strain stress ( $\sigma$ vs. $\varepsilon$ ), was equal to $20 \%$ [11]. Meanwhile, the young modulus with annealing treatment was $194.09 \mathrm{GPa}$. In other words, the engineering strain increased significantly with the annealing treatment compared to the untreated specimen. The annealing treatment will make the specimen ductile so that the strain and reduction of the cross-sectional area increase [7].

Table 1: Tensile strength of 304 stainless steel

\begin{tabular}{ccc}
\hline \multirow{2}{*}{ Material } & \multicolumn{2}{c}{ Stress (MPa) } \\
\cline { 2 - 3 } & Yield (0.2\%) & Ultimate \\
\hline SS 304 Annealed & 220.54 & 594.87 \\
\hline
\end{tabular}

\subsection{Low-Cycle Fatigue Analysis}

The results of the low-cycle fatigue test with different strain amplitude variations are shown in Table 2 under conditions of $0.5 \mathrm{Nf}$. Then, the low-cycle fatigue test was carried out using six variations of strain amplitude: $0.003 \mathrm{~mm} / \mathrm{mm}, 0.005 \mathrm{~mm} / \mathrm{mm}, 0.007 \mathrm{~mm} / \mathrm{mm}, 0.009 \mathrm{~mm} / \mathrm{mm}$, $0.011 \mathrm{~mm} / \mathrm{mm}$, and $0.013 \mathrm{~mm} / \mathrm{mm}$. Based on Table 4.2, cycle value is a benchmark for measuring fatigue life in specimens. The higher the cycle value produced, the longer the durability or lifespan of the specimen. Conversely, a cycle with a low value indicates that the specimen's life is short. Meanwhile, the fatigue testing results on CDS specimens that had been annealed showed that the highest cycle was in the first specimen (CDS304_A1) with a strain 
amplitude of $0.003 \mathrm{~mm} / \mathrm{mm}$ with 48367 cycles. In contrast, the lowest cycle was in the sixth specimen (CDS304_A5) with a strain amplitude of $0.013 \mathrm{~mm} / \mathrm{mm}$ with 268 cycles.

Table 2: LCF Test Results Data on Type 304 Stainless Steel with Annealing

\begin{tabular}{ccccccc}
\hline Specimen & $\begin{array}{c}\text { Strain } \\
\text { Amplitude } \\
(\mathbf{m m} / \mathbf{m m})\end{array}$ & $\begin{array}{c}\text { Frequency } \\
\left(\mathbf{H}_{\mathbf{z}}\right)\end{array}$ & $\begin{array}{c}\text { Plastic } \\
\text { Strains } \\
(\mathbf{m m} / \mathbf{m m})\end{array}$ & $\begin{array}{c}\text { Elastic } \\
\text { Strains } \\
(\mathbf{m m} / \mathbf{m m})\end{array}$ & $\begin{array}{c}\text { Elastic } \\
\text { Modulus } \\
(\mathbf{G P a})\end{array}$ & $\begin{array}{c}\text { Fracture } \\
\text { Cycle (Nf) }\end{array}$ \\
\hline CDS304_A1 & 0.003 & 0.4167 & 0.00193 & 0.00107 & 196.58 & 48367 \\
CDS304_A2 & 0.005 & 0.2500 & 0.00309 & 0.00191 & 198.70 & 4625 \\
CDS304_A3 & 0.007 & 0.1786 & 0.00480 & 0.00221 & 205.27 & 1058 \\
CDS304_A4 & 0.009 & 0.1389 & 0.00591 & 0.00309 & 208.72 & 829 \\
CDS304_A5 & 0.013 & 0.0962 & 0.00949 & 0.00350 & 202.79 & 268 \\
\hline
\end{tabular}

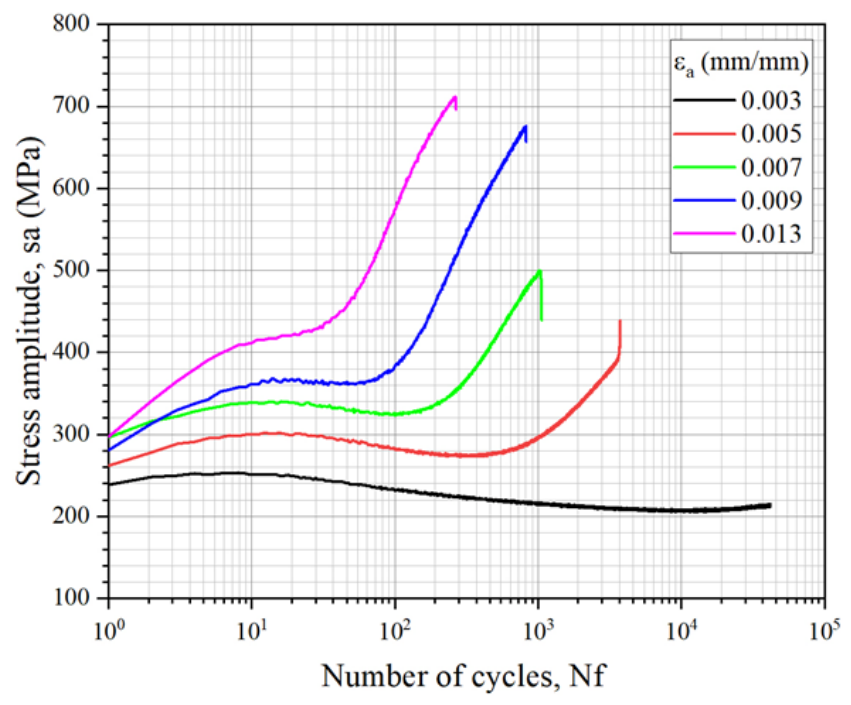

Fig. 4. The relationship of peak stress to the number of cycles of type 304 stainless steel, treated with annealing treatment at low-cycle fatigue tests, with variations in strain amplitude

There was a relationship between the peak stress and the number of cycles in the low-cycle fatigue test. This relationship was used to see the hardening and softening behavior of type 304 stainless steel annealed during low-cycle fatigue testing with a given variation of the strain amplitude. The tested specimens owned the highest plastic strain with high strain amplitudes, namely $0.013 \mathrm{~mm} / \mathrm{mm}, 0.00895 \mathrm{~mm} / \mathrm{mm}$, and $0.00949 \mathrm{~mm} / \mathrm{mm}$. Meanwhile, the smallest plastic strain values were $0.00095 \mathrm{~mm} / \mathrm{mm}$ and $0.00193 \mathrm{~mm} / \mathrm{mm}$. In addition, the specimens tested had the highest elastic strains with high strain amplitudes, namely $0.013 \mathrm{~mm} / \mathrm{mm}$, $0.00405 \mathrm{~mm} / \mathrm{mm}$, and $0.00350 \mathrm{~mm} / \mathrm{mm}$. Meanwhile, the smallest elastic strain values were $0.00205 \mathrm{~mm} / \mathrm{mm}$ and $0.00107 \mathrm{~mm} / \mathrm{mm}$.

In Figure 4, the strain amplitude of 0.003 in cycles 1 to 100 the specimen underwent cyclic hardening, and after that, it was softened to fracture. Similarly, with a strain amplitude specimen of 0.005 , cyclic softening occurred from the beginning to the 200th cycle and, after 
that, underwent progressive cyclic hardening and breaking. Then, in specimens with a strain amplitude of $0.007-0.013$, the cyclic pattern tended to be the same. The low cycle underwent softening and then hardening to fracture, which is a similar phenomenon reported in the literature $[13,14]$.

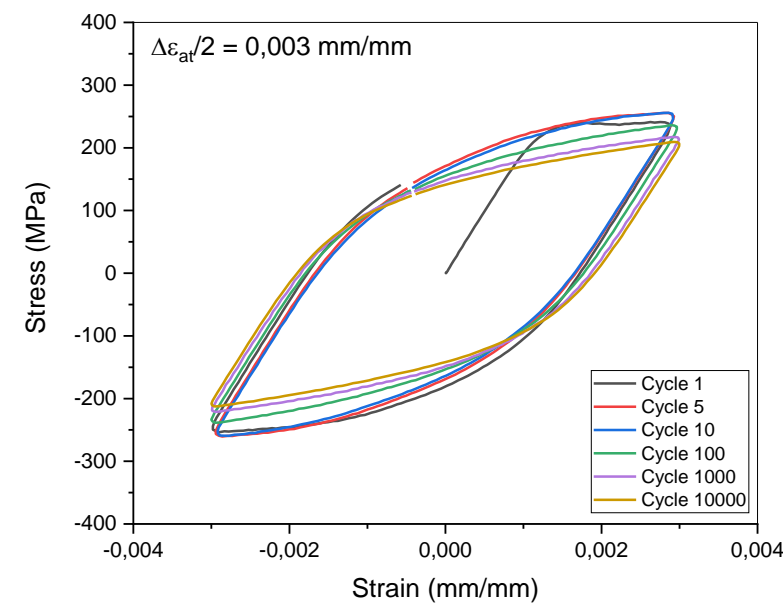

(a)

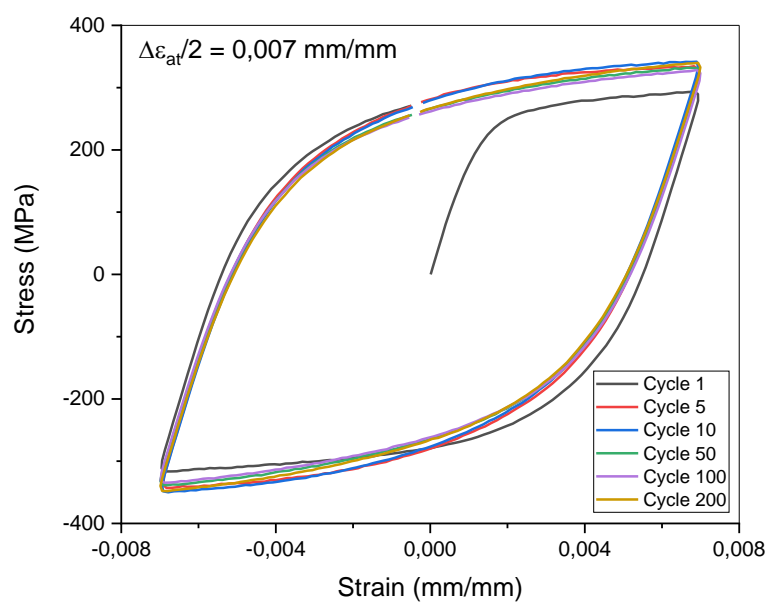

(b)

Fig. 5. The evolution of the stress-strain changes in different cycles under the conditions of the strain amplitude of (a) $0.003 \mathrm{~mm} / \mathrm{mm}$ (b) $0.007 \mathrm{~mm} / \mathrm{mm}$

The hardening and softening behavior of the annealed 304 stainless steel could be analyzed further on the hysteresis curve (stress vs. strain) [10]. Based on Figure 5, the evolution of stressstrain changes in each cycle or the hysteresis curve on the results of the low-cycle fatigue test was found in Figure 5, with a strain amplitude of $0.007 \mathrm{~mm} / \mathrm{mm}$. In the first cycle, 304 stainless steel experienced tensile stress of 293.3 MPa and compressive stress of $-316.53 \mathrm{MPa}$. In the fifth cycle, the steel experienced increased tensile stress of $334.32 \mathrm{MPa}$ and compressive stress of $-343.25 \mathrm{MPa}$. Furthermore, in the tenth cycle, the steel experienced increased tensile stress again to $341.5 \mathrm{MPa}$ and increased compressive stress to $-349.5 \mathrm{MPa}$. The low-cycle fatigue test with a strain amplitude of $0.007 \mathrm{~mm} / \mathrm{mm}$ underwent a large plastic deformation. Characterized by unpredictable crack initiation through a change in stress drop of $10 \%$ from the condition after the stable cycle (half-life), steel also continued to experience an increase in stress before just at the time of failure (failure cycle). Analyzing the fatigue life requires the relationship between the stress amplitude and the total strain amplitude to see the strain hardening material from cyclic loading [9]. The values of the parameters include the cyclic strength coefficient $\left(\mathrm{K}^{\prime}\right)$ and the cyclic strain hardening exponent $\left(n^{\prime}\right)$, obtained from the data based on the lowcycle fatigue test results on half-cycle hysteresis loops with different strain amplitudes, as shown in Figure 6 and Table 3. 


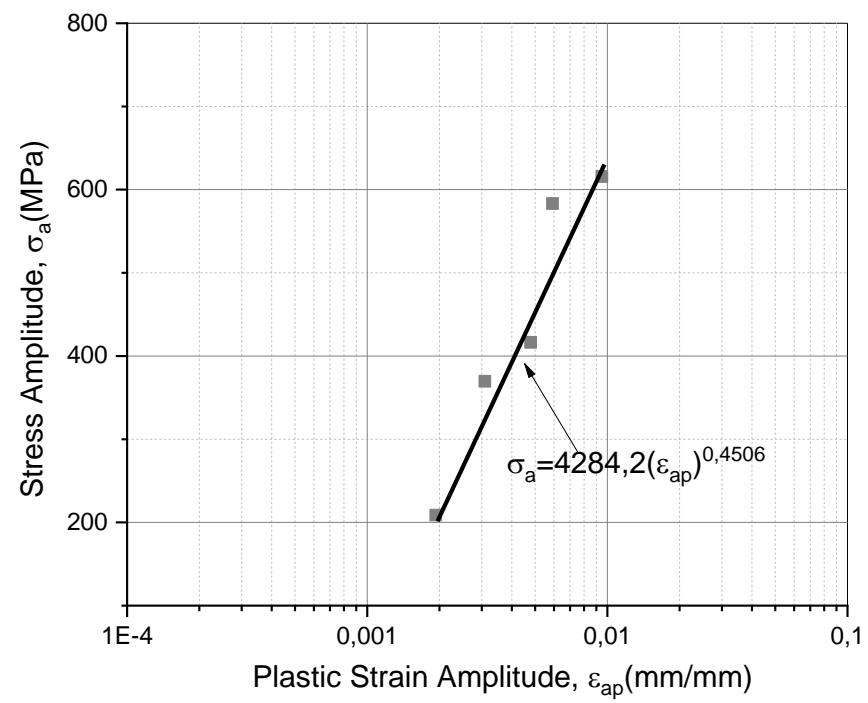

Fig. 6. Graph of cyclic stress amplitude vs. the plastic strain amplitude from the low-cycle fatigue test results using type 304 stainless steel at different strain amplitudes with annealing

Table 3: The parameter value of LCF on 304 Stainless Steel with Annealing Treatment

\begin{tabular}{lc}
\hline Low-cycle fatigue parameters & Value \\
\hline Cyclic strength coefficient, $K^{\prime}(\mathrm{MPa})$ & 4284.2 \\
Fatigue strength coefficient, $\sigma_{f}^{\prime}(\mathrm{MPa})$ & 2640.5 \\
Cyclic strain hardening exponent, $n^{\prime}$ & 0.4506 \\
Fatigue power exponent, $b$ & -0.1205 \\
Fatigue ductility coefficient, $\varepsilon_{f}^{\prime} \mathrm{mm} / \mathrm{mm}$ & 0.0496 \\
Fatigue ductility exponent, $c$ & -0.3179 \\
\hline
\end{tabular}

\section{CONCLUSION}

Annealing treatment of 304 stainless steel decreased tensile strength compared to untreated 304 stainless steel, indicated by yield stress decreased by $55 \%$ and ultimate stress decreased by $18 \%$. On the other hand, the coefficient of cyclic strength $\left(\mathrm{K}^{\prime}\right)$ and the exponential value of cyclic stress (n') increased significantly. The empirical equation for predicting the fatigue life of strain-based annealed 304 stainless steel is:

$$
\Delta \varepsilon_{t}=2640,5\left(2 N_{f}\right)^{-0.1205}+0,0496\left(2 N_{f}\right)^{-0,3179}
$$

\section{ACKNOWLEDGEMENT}

The work was financially supported by Director of Research and Community Service of the Ministry of Research, Technology and Higher Education on Research of Magister Thesis with contract No. 044/SP2H/LT/DRPM/2020.

\section{REFERENCES}

[1] Xu L, Yang S, Zhao L, Han Y, Jing H, Wang K (2020). Low cycle fatigue behavior and microstructure evolution of a novel Fe-22Cr-15Ni austenitic heat-resistant steel, J Mater Res Technol.,9(6):14388-14400.

[2] Nip KH, Gardner L, Davies CM, Elghazouli AY 2010. Extremely low cycle fatigue tests on structural carbon steel and stainless steel. J Constr steel Res., 66(1):96-110.

[3] Yin F, Yang L, Wang M, Zong L, Chang X (2019). Study on ultra-low cycle fatigue behavior of austenitic stainless steel, Thin-Walled Struc., 143:106205. 
[4] Mazánová V, Heczko M, Škorík V, Chlupová A, Polák J, Kruml T (2019). Microstructure and martensitic transformation in $316 \mathrm{~L}$ austenitic steel during multiaxial low cycle fatigue at room temperature, Mater Sci Eng. A, 767:138407.

[5] Xu L, Bao F, Zhao L, Han Y, Jing H, Yu H, Gong X (2021). Characterizing microstructural evolution and low cycle fatigue behavior of $316 \mathrm{H}$ austenitic steel at high-temperatures, J Nucl Mater.,546:152758.

[6] Xie X, Ning D, Sun J (2016). Strain-controlled fatigue behavior of cold-drawn type 316 austenitic stainless steel at room temperature. Mater Charac., 120:195-202.

[7] Li Y, Yuan Y, Wang D, Fu S, Song D, Vedani M, Chen X (2022). Low cycle fatigue behavior of wire arc additive manufactured and solution annealed $308 \mathrm{~L}$ stainless steel, Addit Manufac., $52: 102688$.

[8] Roy SC, Goyal S, Sandhya R, Ray SK (2012). Low cycle fatigue life prediction of 316 L (N) stainless steel based on cyclic elasto-plastic response. Nucl Eng Des., 253:219-225.

[9] Ahmadzadeh GR, Varvani-Farahani A (2016). Fatigue damage and life evaluation of SS304 and Al 7050-T7541 alloys under various multiaxial strain paths by means of energy-based Fatigue damage models. Mech Mater., 98:59-70.

[10] Bondar VS, Dansin VV, Vu LD, Duc ND (2018). Constitutive modeling of cyclic plasticity deformation and low-high-cycle fatigue of stainless steel 304 in uniaxial stress state. Mech Adv Mater Struct., 25(12):1009-1017.

[11] ASTM E8 (2004) Standard Test Methods for Tension Testing of Metallic Materials, West Conshohocken, United States.

[12] ASTM E606 (2004) Standard Practice for Strain-Controlled Fatigue Testing, West Conshohocken, United States.

[13] Annan CV, Beaumont E (2020). Low-cycle fatigue of stainless steel plates under large plastic strain demands, J Build Eng., 29:101160.

[14] Carneiro L, Wang X, Jiang Y (2020). Cyclic deformation and fatigue behavior of 316L stainless steel processed by surface mechanical rolling treatment, Intl J Fat., 134:105469. 